\title{
Estimating the Yield Advantage of High-Yielding Wheat and Maize: The Use of Pakistani On-Farm Yield Constraints Data
}

\author{
JOSEPH G. NAGY*
}

This paper briefly reviews the index number approach to estimating the contribution made by crop development research and then discusses the use of on-farm yield constraint data to measure the rightward shift in the supply curve. Yield constraint data on wheat and maize from Pakistan are used as an illustration.

\section{INTRODUCTION}

The accurate measurement of the yield advantage of new crop varieties over old crop varieties is important in assessing the contribution made by crop development research. Unbiased estimates of the yield advantage of improved crops are difficult to obtain in particular for the high-yielding varieties (HYVs) in the less developed Countries (LDCs). This in turn has led to the questioning of robust rate of returns to crop development research from using the Index number approach $[8,10] .^{1}$

This paper briefly reviews the index number approach to estimating the contribution made by crop development research and then discusses the problems of obtaining accurate yield-advantage figures and the problems of estimating the supply shifter used in the index number approach. The paper then discusses the use of on-farm yield constraint data as a source of data for estimating the yield advantage. Yield constraint data from Pakistan are used as an illustration.

\section{OVERVIEW OF THE INDEX NUMBER APPROACH}

The index number approach (consumer-producer surplus approach) estimates the benefits to agricultural research by measuring the change in consumer surplus

${ }^{*}$ Graduate Research Assistant, Department of Agricultural and Applied Economics, University of Minnesota, St. Paul, Minnesota. The Author gratefully acknowledges the suggestions of Dr. Vernon W. Ruttan and Dr. Carl E. Pray of the University of Minnesota. The author also acknowledges the help of Dr. Riaz Ahmad Khan (member) and Mr. Muhammad Iqbal of the Social Sciences Division, Pakistan Agricultural Research Council.

${ }^{1}$ See Ruttan [12, pp. 242-246] for a summary of rate of return studies. 
(CS) and producer surplus (PS) from a rightward shift in the supply curve that has been brought about by technological change.

The change in CS in Figure 1 is shown by areas $\mathrm{A}+\mathrm{B}$ and is a positive change, given a supply shift from $Q_{s}^{\prime}$ to $Q_{s}$ and a demand curve that is not perfectly elastic. The gain occurs because consumers pay the lower price P0 brought about by the technological change. The change in producers' welfare (PS) is Area C minus Area A. The change in PS is the difference between what is gained because of lower costs per unit of output (Area $C$ ) and the increased quantity marketed $Q_{1}$ to $Q_{0}$ minus the loss incurred from the drop in price from $\mathrm{P}_{1}$ to $\mathrm{P}_{0}$ (Area A). PS may be positive or negative depending on the elasticities of supply and demand. The gross annual research benefit (GARB) is then Area B + Area C.

Annual benefits may be calculated once the following data and information are made available: (1) supply and demand elasticities, (2) yearly price and quantity data, and (3) the annual leftward shift in the actual supply curve $Q_{s}$ in order to establish the pre-innovation supply curve $\mathrm{Q}_{\mathrm{s}}^{\prime}$ (usually called the supply shifter $\left.K\right)^{2}{ }^{2}$ An internal rate of return may then be calculated from the annual stream of benefits derived from the index number approach and the associated annual stream of research costs of the new technology.

The index number approach has gone through an evolution since the hybridcorn study by Griliches [5] in 1958. This "first generation" model used a unitary elastic demand curve and estimated returns for both a perfectly elastic and an inelastic supply curve with a crude 'guesstimate' of the supply shifter $K$. Although the model was crude, Griliches [5], along with the pioneering work by Schultz [14], started people thinking about the returns to research and led to "second generation" models that gave more attention to elasticities of supply and demand, estimation of expenditures, the shift factor $K$ and the change in the distribution of income from technological change. Among the early second-generation models were Peterson's poultry study [11], Ayer and Schuh's Brazilian cotton study [2], Akino and Hayami's study on rice in Japan [1] and Schmitz and Seckler's tomato-harvester study [13]

\section{ESTIMATION OF THE SHIFT PARAMETER, $K$}

The index number approach using the horizontal supply shift method requires knowledge of what the production of a certain commodity would have been, given that producers did not have access to the innovation under study. The most popular

${ }^{2} K$ is traditionally known as the supply shifter as in the articles by Griliches, Peterson and Ayer and Schuh. However, Akino and Hayami interpret $K$ as a production function shifter. See Ayer and Schuh. However, Akino and Hayami
the appendices to Hayami and Akino, page 52.

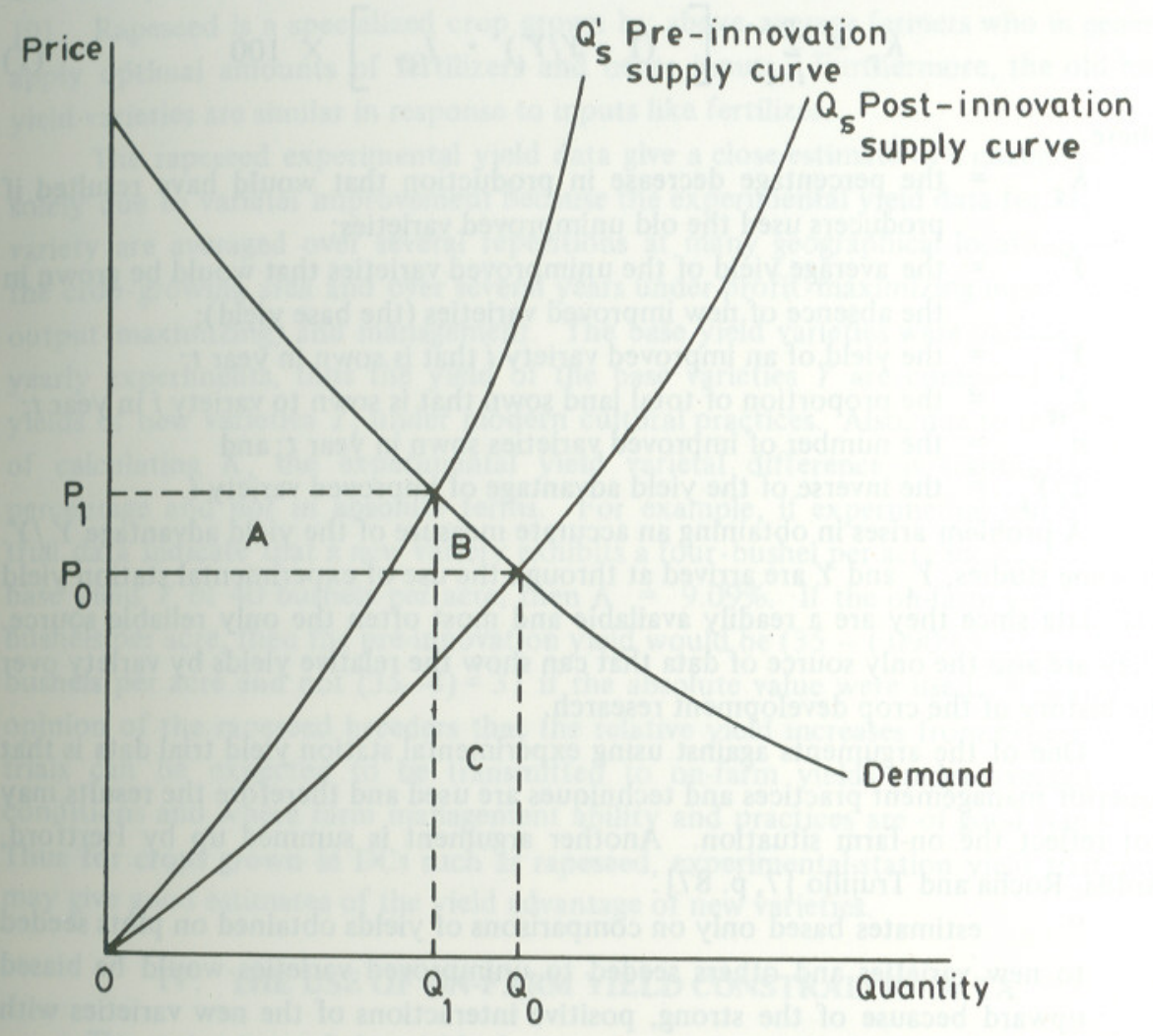

Figure 1. Model of Returns from Crop Varietal Improvement. 


\section{CORRECTION}

On p. 181 of our Autumn 1983 issue, letters B and C in Figure 1 of Joseph G. Nagy's article were, in the process of cartographic reproduction, wrongly placed. The Figure should have appeared as it appears below. The error is sincerely regretted. - Editor

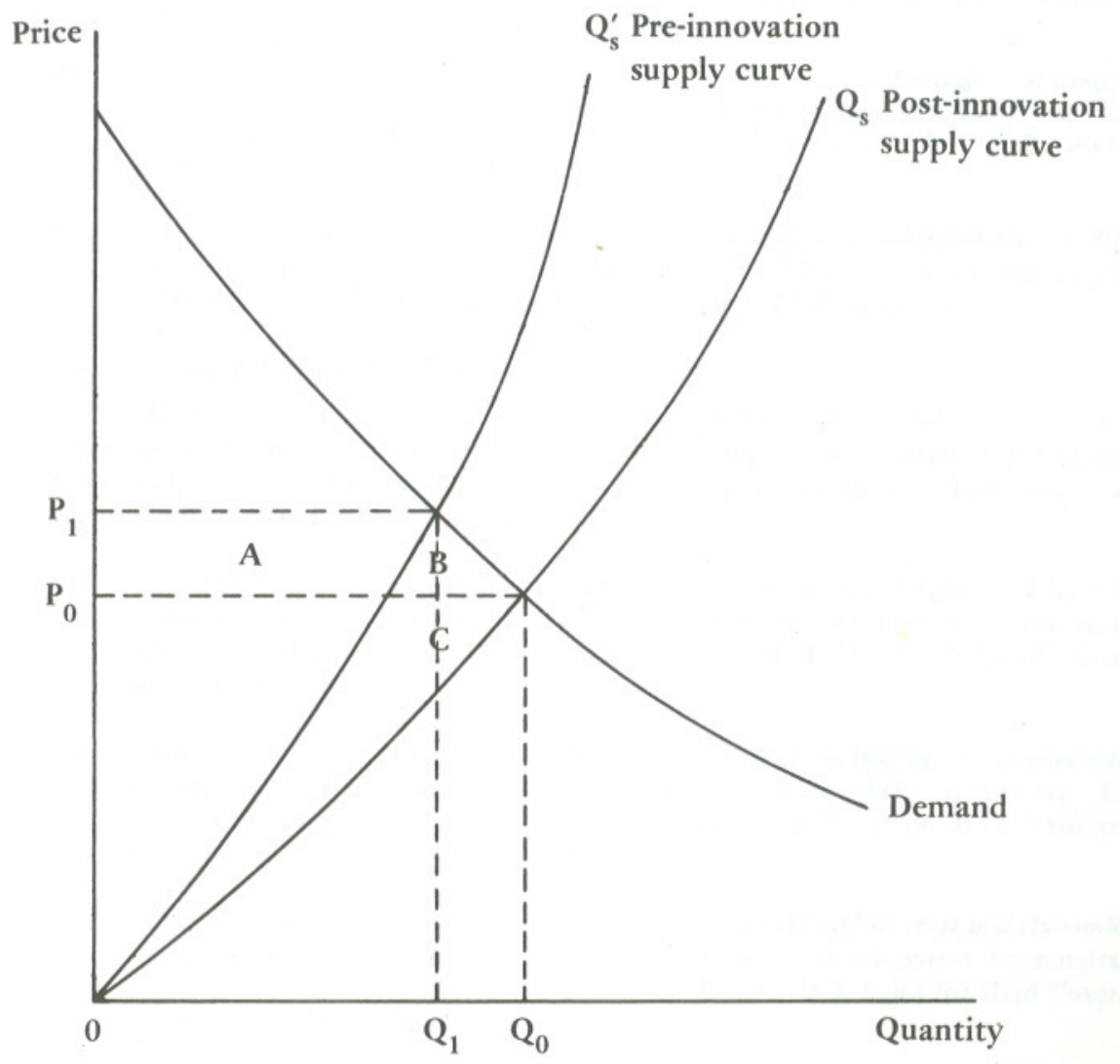

Figure 1. Model of Returns from Crop 
way in specifying the shift from $Q_{s}$ to $Q_{s}^{\prime}$ in Figure 1 follows that of the Ayer-Schuh and Akino-Hayami models as indicated below:

$$
K_{\tau}=\sum_{i=1}^{n}\left[\left(1-Y / Y_{i}\right) \cdot L_{i \tau}\right] \times 100
$$

where

$K_{\tau} \quad=$ the percentage decrease in production that would have resulted if producers used the old unimproved varieties;

$Y \quad=$ the average yield of the unimproved varieties that would be grown in the absence of new improved varieties (the base yield);

$Y_{i} \quad=$ the yield of an improved variety $i$ that is sown in year $t$;

$L_{i \tau}=$ the proportion of total land sown that is sown to variety $i$ in year $t$;

$n=$ the number of improved varieties sown in year $t$; and

$Y / Y_{i}=$ the inverse of the yield advantage of improved variety $i$.

A problem arises in obtaining an accurate measure of the yield advantage $Y_{i} / Y$ In some studies, $Y_{i}$ and $Y$ are arrived at through the use of experimental station yield trial data since they are a readily available and most often the only reliable source. They are also the only source of data that can show the relative yields by variety over the history of the crop development research.

One of the arguments against using experimental station yield trial data is that superior management practices and techniques are used and therefore the results may not reflect the on-farm situation. Another argument is summed up by Hertford, Ardila, Rocha and Trujillo [7, p. 87].

“... estimates based only on comparisons of yields obtained on plots seeded

to new varieties and others seeded to unimproved varieties would be biased upward because of the strong, positive interactions of the new varieties with such inputs as fertilizers and water."

The argument by Hertford $e t$ al. is that the yield advantage estimate would be biased upward because the estimate may also include the contribution made by inputs such as fertilizers and water. To account for this problem, they estimated the yield advantages of new varieties in Colombia by estimating production functions of yield as a function of new varieties and other inputs. For example, using data from commercial rice trial plots, they estimated yield as a function of 20 variables which included size of plot, seeding rate, seven seed-variety variables, two time variables and four variables to differentiate locations. In comparing $K$ obtained from equation (1) and the $K$ obtained from the regression results for rice, the former was on an average twice that of the latter. ${ }^{3}$

The use of experimental station yield trial data does not provide a good estimate of the shift parameter $K$ in less developed countries (LDCs) because of the

\footnotetext{
${ }^{3}$ For an alternate procedure for estimating $K$, see K. M. Scobie and Rafael Posada T. [15].
}

previous arguments. However, in the case of some crops in developed countries (DCs) experimental station yield trial data do offer a good estimate of the yield advantage and shift parameter $K$. Take, for example, the case of rapeseed breeding in Canada [9]. Rapeseed is a specialized crop grown by above-average farmers who in general apply optimal amounts of fertilizers and other inputs. Furthermore, the old base yield varieties are similar in response to inputs like fertilizer.

The rapeseed experimental yield data give a close estimate of a change in yield solely due to varietal improvement because the experimental yield data for each new variety are averaged over several repetitions at many geographical locations within the crop-growing area and over several years under profit-maximizing input use (not output-maximizing) and management. The base yield varieties were included in the yearly experiments, thus the yield of the base varieties $Y$ are compared with the yields of new varieties $Y_{i}$ under modern cultural practices. Also, due to the method of calculating $K$, the experimental yield varietal difference is transmitted as a percentage and not in absolute terms. For example, if experimental station yield trial data indicate that a new variety exhibits a four-bushel per acre increase over the base yield $Y$ of 40 bushels per acre, then $K=9.09 \%$. If the on-farm yield was 35 bushels per acre, then the pre-innovation yield would be $(35-(.0909 \times 35))=31.82$ bushels per acre and not $(35-4)=31$ if the absolute value were used. It is also the opinion of the rapeseed breeders that the relative yield increases from experimental trials can be expected to be transmitted to on-farm yields under average farm conditions and where farm management ability and practices are of good standards. Thus for crops grown in DCs such as rapeseed, experimental-station yield trial data may give good estimates of the yield advantage of new varieties.

\section{THE USE OF ON-FARM YIELD CONSTRAINTS DATA}

The estimation of the yield advantage using the method of Hertford et al. does require substantial data which are not readily available in most LDC countries. A new source of data may exist for the estimation of the yield advantage due to varietalyield-increasing research. The source of data is the "On-Farm Yield Constraints Studies" that are now being conducted in several LDCs.

The main focus of the On-Farm Yield Constraint studies is on measuring the on-farm yield gap between existing recommended practices and existing farm practices. The analysis shows the contribution to output of individual test factors that make up the gap between existing farm practices and recommended practices. Factors such as the level of fertilizer use, weeding, planting time period and planting
depth have been analyzed [4].

Several on-farm yield constraint trials have also included variety as one of the test factors. Furthermore, some of the trials have used pre-HYVs vs. post-HYVs as the test factors. The information gained from such trials can be used in determining 
the yield advantage of HYVs. Table 1 and Table 2 show the results of wheat yield constraint trials in Pakistan on barani (rainfed) and irrigated lands respectively. Three test factors are involved in the trials: (1) Farmers' variety (tall variety) vs. recommended HYV variety; (2) Farmer fertilizer application rate vs. recommended rates: and (3) Farmers' weeding practice vs. recommended weeding practice. All other inputs are held constant at a level of good farm practices and input use. The trials were conducted on farmer fields.

The information contained in Tables 1 and 2 can be used in calculating the wheat-yield advantage of HYVs in Pakistan. ${ }^{4}$ By rearranging the treatments as is done in Table 3, the contribution to yield from the use of HYVs under four different input levels can be established. For example, Category I in Table 3 holds constant the two test factors of fertilizer and weeding at the farmers' input levels of $F 1$ and W1 while allowing the variety test factor to change from the farmers' variety V1 to the recommended HYV V5. The yield advantage of using the HYV holding the other test factors at F1W1 can then be calculated and is 16.1 percent or 1.161 and 55.3 percent or 1.553 for unirrigated and irrigated land respectively.

Table 1

Wheat Yield Constraint Trial Data on Rainfed Land, Pakistan

\begin{tabular}{lcc}
\hline Treatments & Yield Index \\
\hline 1. V1F1W1 & 100.0 \\
2. V1F5W1 & 128.2 \\
3. V1F1W5 & 107.1 \\
4. V1F5W5 & 136.5 \\
5. V5F1W1 & 116.1 \\
6. V5F5W1 & 148.0 \\
7. V5F1W5 & 128.3 \\
8. & V5F5W5 & 155.7 \\
\hline
\end{tabular}

Six locations, three replications (Punjab and NWFP locations).

$\mathrm{V} 1=$ Farmers Variety $(\mathrm{C}-591)$

$\mathrm{F} 1=$ Farmers Fertilizer ( $50 \mathrm{~N}$ and $26 \mathrm{Plbs} / \mathrm{acre})$

$\mathrm{W} 1=$ Farmers Weeding (no practice)

V5 = Recommended Variety (Lyallpur-73)

$\mathrm{F} 5=$ Recommended Fertilizer (101N and 75P lbs/acre)

W5 $=$ Recommended Weeding Practice (two weedings)

Source: M. Manzoor Ali, On-Farm Yield Constraints Research in Pakistan: Pakistan Agricultural Research Council, Islamabad.

${ }^{4}$ Unfortunately, the wheat yield constraint data presented in Tables 1 and 2, do not cover move locations. For illustrative purposes, the data are used as proxies for overall Pakistan data.
Table 2

Wheat Yield Constraint Trial Data on Irrigated Land, Pakistan

\begin{tabular}{lll}
\hline \multicolumn{2}{c}{ Treatments } & Yield Index \\
\hline 1. & V1F1W1 & 100.0 \\
2. & V1F5W1 & 108.9 \\
3. & V1F1W5 & 110.7 \\
4. & V1F5W5 & 101.8 \\
5. & V5F1W1 & 155.3 \\
6. & V5F5W1 & 164.3 \\
7. & V5F1W5 & 150.0 \\
8. & V5F5W5 & 167.8 \\
\hline
\end{tabular}

Four replications (Sind locations).

$\mathrm{V} 1=$ Farmers Variety (mainly C-591 and other tall varieties)

$\mathrm{F} 1=$ Farmers Fertilizer ( $50 \mathrm{~N}$ and $20 \mathrm{P} \mathrm{lbs} / \mathrm{acre})$

$\mathrm{W} 1=$ Farmers Weeding (no practice)

V5 $=$ Recommended Variety (ZA-77)

$\mathrm{F} 5=$ Recommended Fertilizer ( $120 \mathrm{~N}$ and $60 \mathrm{P} \mathrm{lbs} / \mathrm{acre})$

$\mathrm{W} 5=$ Recommended Weeding Practice (one hand weeding)

Source: Natali, A. H., Annual Progress Report, 1980-81, Wheat Section, Agricultural Research Institute, Tandojam, Pakistan.

To estimate the shift parameter $K$ using the information from Table 3, equation (1) will have to be respecified. First, informtion of the yield advantage by variety is not available and therefore the old tall variety, C-591, and, the two HYVs, LYP-73 and ZA-77 will become the proxies for the base yield $(Y)$ and all HYVs $\left(Y_{i}\right)$ respectively. The C-591 variety was one of the most popular pre-semi-dwarf varieties grown in Pakistan and its average yield and characteristics are very similar to those of other tall varieties. The average yield and characteristics of LYP-73 and ZA-77 on average are also very similar to other semi-dwarf varieties grown in Pakistan. Secondly, instead of weighting each variety's yield advantage by the proportion of land it was sown to in year $t$, an overall yield advantage figure would be obtained by weighting the yield advantage of each of the four input categories in Table 3 by the proportion of land sown to HYVs in each category. However, in the case of Pakistan, accurate figures of the land sown to each input category of Table 3 are not available. When equally weighted, the yield advantage would be 1.164 and 1.517 for unirrigated and irrigated land respectively. However, in Pakistan, most of the total production from the area sown to the HYVs of wheat would come from input 
categories I and III. Equal weighting of categories I and III would give a yield advantage estimate of 1.180 and 1.455 for unirrigated and irrigated land respectively.

The yield advantage for irrigated and unirrigated land can then be weighted by the area of unirrigated land sown to the HYVs and the area of irrigated land sown to HYVs to produce the overall yield advantage due to the varietal improvement of wheat. About 10 percent of all the HYVs sown in Pakistan are sown on unirrigated land. Thus, the overall yield advantage is 1.43 .

The shifter $k$ would then by found yearly using the following formula. ${ }^{5}$

$$
k_{\tau}=1-\left[\frac{1}{\left((1-1.43) \times L H Y V_{\tau}\right)+1}\right]
$$

where

$k_{\tau}=$ The percentage decrease in production that would have resulted if producers used the old tall wheat varieties; and

$L H Y V_{\tau}=$ The proportion of land sown to HYVs in year $\tau$

Table 3

Wheat Yield Advantages from Varietal Improvement Research

\begin{tabular}{|c|c|c|c|c|c|}
\hline \multirow{2}{*}{$\begin{array}{l}\text { Input } \\
\text { Category }\end{array}$} & \multirow[b]{2}{*}{ Treatments } & \multicolumn{2}{|c|}{ Unirrigated } & \multicolumn{2}{|c|}{ Irrigated } \\
\hline & & $\begin{array}{l}\text { Yield } \\
\text { Index }\end{array}$ & $\begin{array}{c}\text { Yield } \\
\text { Advantage }\end{array}$ & $\begin{array}{l}\text { Yield } \\
\text { Index }\end{array}$ & $\begin{array}{c}\text { Yield } \\
\text { Advantage }\end{array}$ \\
\hline I & $\begin{array}{l}\text { V1F1W1 } \\
\text { V5F1W1 }\end{array}$ & $\begin{array}{l}100.0 \\
116.1\end{array}$ & 1.161 & $\begin{array}{l}100.0 \\
155.3\end{array}$ & 1.553 \\
\hline II & $\begin{array}{l}\text { V1F5W1 } \\
\text { V5F5W1 }\end{array}$ & $\begin{array}{l}128.2 \\
148.0\end{array}$ & 1.154 & $\begin{array}{l}108.9 \\
164.3\end{array}$ & 1.509 \\
\hline III & $\begin{array}{l}\text { V1F1W5 } \\
\text { V5F1W5 }\end{array}$ & $\begin{array}{l}107.1 \\
128.3\end{array}$ & 1.198 & $\begin{array}{l}110.7 \\
150.0\end{array}$ & 1.356 \\
\hline IV & $\begin{array}{l}\text { V1F5W5 } \\
\text { V5F5W5 }\end{array}$ & $\begin{array}{l}136.5 \\
155.7\end{array}$ & 1.141 & $\begin{array}{l}101.8^{1} \\
167.8\end{array}$ & 1.648 \\
\hline
\end{tabular}

Source: Tables 1 and 2 .

${ }^{1}$ Treatment V1F5W5 under irrigated conditions would appear to be lower than expected thus biasing the yield advantage of input category IV upward.

${ }^{5}$ Calculations of the annual shifter $k_{\tau}$ and rates of return to research have been calculated but not presented. They can be found in "Productivity and Rate of Return to the Agriculture Research System of Pakistan," Ph.D. Dissertation, University of Minnesota (forthcoming).
In comparison to the 1.43 wheat yield advantage figure derived from yield constraints data, Sidhu's production function analysis indicates yield advantage figures ranging from 1.23 to 1.45 for wheat in the Indian Punjab in 1967-68 and Colombian research analysis in 1971 suggested a 1.46 figure for semi-dwarf wheat varieties [3].

A comparison of the wheat yield advantage using the on-farm yield constraints data can be made with the yield advantage calculated from experimental station yield trial data from Pakistan. The average experimental research station yield in $\mathrm{kg} / \mathrm{acre}$ of the dominant pre-HYV wheat varieties of C228, C217, C591, C518, C271 and $\mathrm{C} 273$ is 890.6. The average experimental research station yield in $\mathrm{kg} / \mathrm{acre}$ of the dominant HYVs of Mexi-Pak Ch-70. Blue Silver, SA-42, Y-ecora and Pari-73 is 1697.5. ${ }^{6}$ The simple calculation of the yield advantage using experimental research station data is 1.91 which is more than twice the yield advantage of the 1.43 calculated using on-farm yield constraints data.

Table 4

Maize Yield Advantages from Varietal Improvement

\begin{tabular}{|c|c|c|c|c|c|}
\hline \multirow[b]{2}{*}{$\begin{array}{c}\text { Input } \\
\text { Category }\end{array}$} & \multirow[b]{2}{*}{ Treatments $^{1}$} & \multicolumn{2}{|c|}{ Punjab } & \multicolumn{2}{|c|}{ NWFP } \\
\hline & & $\begin{array}{l}\text { Yield }^{2} \\
\text { Index }\end{array}$ & $\begin{array}{c}\text { Yield } \\
\text { Advantage }\end{array}$ & $\begin{array}{l}\text { Yield }^{3} \\
\text { Index }\end{array}$ & $\begin{array}{c}\text { Yield } \\
\text { Advantage }\end{array}$ \\
\hline I & $\begin{array}{l}\text { V1P1 } \\
\text { V5P1 }\end{array}$ & $\begin{array}{l}100.0 \\
123.7\end{array}$ & 1.237 & $\begin{array}{l}100.0 \\
115.7\end{array}$ & 1.157 \\
\hline II & $\begin{array}{l}\text { V1P5 } \\
\text { V5P5 }\end{array}$ & $\begin{array}{l}135.2 \\
167.2\end{array}$ & 1.236 & $\begin{array}{l}135.5 \\
161.3\end{array}$ & 1.190 \\
\hline
\end{tabular}

Source: Progress Report, Cooperative Research Program, Maize, Millets and Sorghum, 1975-1981. Pakistan Agricultural Research Council, Islamabad, 1981 and The Tenth Inter-Asian Corn Improvement Workshop, Agricultural Research Council, Islamabad, 1975.

${ }^{1} \mathrm{~V} 1=$ Unimproved Farmers Variety

V5 $=$ Recommended Varieties for each Province

P1 $=$ Farmers Practices

P5 = Recommended Practices (line sowing, appropriate plant population, $66 \mathrm{~N}$ and $33 \mathrm{P}$ $\mathrm{kg} / \mathrm{ha}$ and plant protection insecticide).

${ }_{3}^{2}$ Two years of data, 84 locations in first year and 6 locations in second year.

tions in the thears of data; 458 locations in first year, 326 locations in second year, 285 locations in the third year, locations not available for fourth year.

${ }^{6}$ Experimental yield trial data from Dr. M. A. Bajwa, Director, Wheat Research Institute, Faisalabad, Pakistan 
A similar procedure can be used to calculate the yield advantage from crop development research for maize. Table 4 indicates the yield advantage for maize in the Punjab and NWFP which are the two major maize-producing provinces in Pakistan. The source of maize data in Table 4 does not allow a breakdown into more than two categories. However, the maize data are pooled over several years and over more locations than for wheat. Unfortunately, no other source of maize yield advantage figures are available for comparison. Calculation of a shift factor $k$ would utilize a similar formula as that presented in equation (2).

\section{SUMMARY AND CONCLUSIONS}

The index number approach estimates the benefits to agricultural research by measuring the change in consumer and producer surpluses from a rightward shift in the supply curve brought about through technological change. The challenge is to accurately measure the shift in the supply curve that is solely due to the new technological advance under study. In the case of yield-increasing crop development research, an estimate of the yield advantage of the new variety solely due to yield. increasing research is required. Problems exist in obtaining accurate yield advantage estimates using readily available experimental station yield trial data for those crops with strong positive interactions with inputs such as fertilizer and water. This problem has been overcome by estimating production functions of a yield as a function of new varieties and other inputs.

The estimation of the yield advantage using the production function approach does, however, require a substantial amount of data. Another source of data to estimate the yield advantage is the on-farm yield constraint studies that are now being done in many LDCs. The case of obtaining the wheat yield advantage of HYVs in Pakistan was illustrated and compared favourably with previous work

Admittedly, the on-farm yield constraints data used in the illustration do have faults. First, the wheat trials are for one year only at limited locations. The accuracy of the yield advantage estimates would have been enhanced had more years of data been available at more locations throughout Pakistan for both wheat and maize. Secondly, other yield constraint factors such as tillage, method of sowing and fertilizer applications at lower and at a zero rate, should be included in the trials.

Although on-farm yield constraint data could be designed better if the purpose in mind was to solely estimate the yield advantage of the HYVs, the data give a fair representation of the contribution of wheat HYVs to the increased overall yield that has taken place in Pakistan. With the knowledge that on-farm yield constraint data can be used to compute yield advantage figures, agriculture economists in need of such data and involved in setting up on-farm yield trials can specifically design the trials to also meet their requirements.

\section{REFERNECES}

1. Akino, M., and Y. Hayami, "Efficiency and Equity in Public Research: Rice Breeding in Japan's Economic Development". American Journal of Agricultural Economics. Vol. 57. 1975

2. Ayer, H.W., and G. Edward Schuh. "Social Rates of Return and Other Aspect of Agricultural Research: The Case of Cotton Research in Sao Paulo, Brazil". American Journal of Agricultural Economics. Vol. 54. 1972.

3. Dalrymple, D. "Impact of Research on Wheat and Rice Production". In T.M Arndt, D.G. Dalrymple, and V.W. Ruttan (eds.), Resource Allocation and Productivity in National and International Agricultural Research. Minneapolis. University of Minnesota Press. 1977.

4. DeDatta, Gomez, Hardt and Barker. Methodology for an Integrated Experi ment-Survey on Rice Yield Constraints. Manila: International Rice Research Institute.

5. Griliches, Z. "Research Costs and Social Returns: Hybrid Corn and Related Innovations". Journal of Political Economics. Vol. 66. 1958.

6. Hayami, Y., and M. Akino, "Organization and Productivity of Agricultural Research Systems in Japan”. In T.M. Arndt, D.G. Dalrymple and V.W. Ruttan (eds.), Resource Allocation and Productivity in National and International Agricultural Research. Minneapolis: University of Minnesota Press. 1977.

7. Hertford, R., J. Ardila, A. Rocha, and L. Trujillo. "Productivity of Agricultural Research in Colombia". In T. M. Arndt, D. G. Dalrymple and V. W. Ruttan (eds.), Resource Allocation and Productivity in National and International Research. Minneapolis: University of Minnesota Press. 1977.

8. Jarrett, F.G., and R.K. Lindner "Research benefits revisited". Review of Marketing and Agricultural Economics. Vol. 45. December 1977. 167-178.

9. Nagy, J.G., and W.H. Furtan. "Economic Costs and Returns From Crop Development Research: The Case of Rapeseed Breeding in Canada". Cana dian Journal of Agricultural Economics. Vol. 26. 1978.

10. Pasour Jr., E.C. and M. A. Johnson. "Bureaucratic Productivity: The Case of Agriculture Revisited”. Public Choice. Vol. 39. 1982.

11. Peterson, W.L. "Returns to Poultry Research in the United States". Journal of Farm Economics Vol. 49. 1967.

12. Ruttan, V.W. Agriculture Research Policy. Minneapolis: University of Minne sota Press. 1982.

13. Schmitz, A., and D. Seckler. "Mechanical Agriculture and Social Welfare: The Case of the Tomato Harvester". American Journal of Agricultural Economics. Vol. 52. 1970. 
14. Schultz, T. W. The Economic Organization of Agriculture. New York: McGraw-Hill. 1953.

15. Scobie, G.M., and R.T. Posada. "The Impact of Technical Change of Income Distribution: The Case of Rice in Colombia". American Journal of Agricultural Economics. Vol. 60. 1978. 